\title{
Piedras sagradas. Sacra saxa. Creencias y ritos en peñas sagradas, Huesca: Diputación-Instituto de Estudios Altoaragoneses, 2018-. $<\mathrm{http}: / /$ www.piedras-sagradas.es $>$
}

Los tiempos en que el papel impreso y encuadernado en libros o revistas era receptáculo y vehículo prácticamente exclusivo del conocimiento científico y de la bibliografía académica van quedando atrás, y a un ritmo que gana celeridad de día en día. Las plataformas internáuticas, con sus posibilidades de contenidos multimedia y con el incremento incesante (cuantitativo y cualitativo) de su ductilidad y de sus funciones, asociadas a cada vez más proyectos científicos, comenzaron hace no demasiados años a disputar el territorio al soporte en papel. Y parece que no están tan lejos los días en que podrán hasta suplantarlo por completo.

El portal Piedras sagradas. Sacra saxa. Creencias y ritos en peñas sagradas, que se halla alojado desde su nacimiento en 2018 en la dirección electrónica <http://www.piedras-sagradas.es/> es una demostración contundente de que, sin necesidad de mover una sola hoja de papel, es posible contar hoy con una herramienta de conocimiento (en este caso de conocimiento etnográfico-antropológico y geográficohistórico, esencialmente) poderosísima, capaz de contener y de gestionar mucha más y más plural información que la que pudiera hallar acogida en un grueso libro e incluso en una enciclopedia completa.

En su fase de desarrollo actual, el portal Piedras sagradas ofrece a quien quiera pasearse por él información profusa y compleja acerca de centenares espacios con piedras o con conjuntos de piedras que han sido señalados en los rincones más remotos de la provincia de Huesca como geografías asociadas desde tiempo inmemorial por el ser humano a creencias y relatos (leyendas, cuentos, supersticiones) de tipo mágico-religioso, y a rituales y fiestas que tenían que ver con la protección, la fecundación, la sanación, el culto a los muertos, etc. Cada uno de esos espacios es minuciosamente catalogado y descrito conforme a criterios rigurosos y cruzados sobre los que enseguida obtendremos más detalles. ¿Cuántas páginas en papel serían precisas para albergar tal caudal de información? ¿Y qué índices y de qué complejidad debería llevar el libro o la enciclopedia resultantes, para intentar competir (misión que se revelaría, a la postre, imposible) con las posibilidades interactivas de un portal virtual?

Piedras sagradas funciona, además, en un formato abierto que, al contrario de lo que permite el recinto acotado y rígido del libro, está siempre dispuesto a la mejora, a la ampliación, a la actualización. Se trata de un palimpsesto ideal, de una obra colectiva e inacabable en el plano no solo de la comunidad que la construye hoy, sino también de las promociones, quién sabe cuántas, que deberán continuar la labor en el futuro. Y todo ello sin que el receptor tenga que pagar otro precio más que el de su ordenador y el de su conexión a internet, y con la ventaja de que tendrá el acceso siempre franco e inmediato, sin que importe el momento ni el país del acceso.

Contamos ya en España y en el mundo hispánico con portales audiovisuales, cada vez más tecnológicamente desarrollados y con mejores contenidos, que están transformando de manera radical los modos de hacer y de proyectar el conocimiento en los campos de la etnografía y de la literatura popular. Los más sofisticados y de mayores 
alcances son, sin duda, el Corpus de Literatura Oral (CLO), de la Universidad de Jaén, que dirige el profesor David Mañero; y el Laboratorio Nacional de Materiales Orales (LANMO) de la ENES-UNAM Morelia (México), que dirigen los profesores Berenice Granados y Santiago Cortés. Pero, además de estos, proliferan los portales, algunos muy profesionales (alojados en páginas de universidades, centros de investigación y museos) y otros más modestos (sustentados por ayuntamientos, asociaciones e investigadores independientes) que están contribuyendo, cada uno a su modo pero por lo general con resultados excelentes, a la recuperación de nuestro patrimonio etnográfico en condiciones muy superiores a las que era posible cuando se contaba con el soporte exclusivo del papel.

Ahora bien: este portal de Piedras sagradas. Sacra saxa. Creencias y ritos en peñas sagradas va mucho más allá, se asoma a nuevos y vertiginosos horizontes, pone a prueba nuevas metodologías y tecnologías, y permite miradas y apreciaciones totalmente diferentes de nuestra cultura patrimonial. No se trata solo de un repositorio sofisticadamente audiovisual como son, esencialmente, muchos otros portales. Piedras sagradas se autodefine, en su página de inicio, como un portal web que

ofrece un completo catálogo de todas las peñas sagradas conocidas en la provincia de Huesca. Diversos buscadores y un mapa interactivo con la localización exacta de cada punto permiten acceder a sus correspondientes datos históricos y antropológicos, acompañados de galerías fotográficas, producto del trabajo de los investigadores Eugenio Monesma, José Miguel Navarro y Josefina Roma.

Se queda muy corta esta descripción. Porque, para empezar, el «catálogo» y los «datos históricos y antropológicos, acompañados de galerías fotográficas» anunciados con palabras tan escuetas están construidos y elaborados con una sistematicidad y un rigor importantes, y con un detalle y profundidad de alto nivel científico en la información.

No en vano el portal está asociado a empeños académicos sobresalientes, como aquel precursor e inolvidable encuentro científico del que nació el libro Sacra saxa. Creencias y ritos en peñas sagradas. Actas del Coloquio Internacional celebrado en Huesca del 25 al 27 de noviembre de 2016, eds. Martín Almagro-Gorbea y Ángel Gari Lacruz (Huesca: Instituto de Estudios Altoaragoneses, 2017).

El mapa interactivo permite la localización y la visualización de diferentes capas (satélite, fotografía aérea, topográfico, etc.) en escalas tan generales o tan de detalle como el usuario y su opción de zoom elijan, de cada una de las piedras o de los conjuntos de piedras catalogadas.

Algo que no he visto aplicado, hasta ahora, a ningún repositorio de información etnográfica ni de España ni de Hispanoamérica, ni tampoco de otros lugares del mundo.

La información que al respecto ofrece la misma página es esta:

El mapa interactivo es una herramienta interdisciplinar concebida con el doble objetivo de aportar información a los investigadores y de poner en valor el patrimonio de las piedras sagradas mediante su divulgación.

Presenta las 206 piedras sagradas localizadas hasta la fecha en la provincia de Huesca. Están descritas en 241 fichas, complementadas con más de 1.500 fotografías, 13 vídeos con tomas aéreas y un audiovisual sobre el amplio escenario mítico-legendario del Salto de Roldán, que ilustran la variedad y riqueza de este patrimonio. Determinados lugares cuentan con dos fichas complementarias, correspondientes al trabajo de diferentes investigadores. 
Las coordenadas incorporadas (latitud-longitud ETRS89 en grados decimales y ETRS89 UTM) permiten localizar con precisión los lugares en la cartografía, así como las informaciones adecuadas para llegar a los espacios mítico-legendarios marcados en el mapa.

La información ha sido recogida en 9 comarcas, 82 municipios y 127 localidades. portal:

Con respecto a la navegación por los mapas, esto es lo que anuncia el propio

Se ofrece un mapa general de toda la provincia, que incluye todas las piedras sagradas, y nueve mapas comarcales. La navegación a través de cualquiera de ellos permite localizar los lugares de interés y consultar los contenidos de todas las fichas asociadas a ellos. Según los niveles de zoom, se agrupan geográficamente los diferentes puntos registrados. A medida que nos acercamos, es posible visualizar la localización exacta de cada elemento y acceder a toda la información asociada.

Búsquedas. Las piedras sagradas también pueden localizarse a partir de distintos tipos de consulta: por palabras clave, por localización territorial (comarca, municipio y localidad) y por tipologías funcionales y morfológicas.

En relación con las posibilidades de búsqueda conviene saber que se pueden hacer, además de sobre el propio mapa, con un buscador de «Tipos morfológicos» que distingue estas categorías:
Conjunto pétreo
Cueva artificial
Cueva natural
Eremitorio
Ermita / Iglesia
Grabados en roca
Huellas
Megalito
Montón de piedras
Pareidolia
Piedra
Piedra exenta
Poblado

Hay además un buscador de «tipos funcionales» que distingue estas otras categorías:

\author{
Apotropaicas \\ Curativas \\ Espacios Sacralizados \\ Fecundantes \\ Funerarias \\ Otras \\ Pareidolias \\ Pedagógicas \\ Rituales \\ Simbólicas
}


Las posibilidades de búsqueda, combinando el catálogo, el mapa interactivo, el buscador de tipos morfológicos, el de tipos funcionales, el de localidades, y las coordenadas de latitud, longitud y zona UTM, permiten, en fin, llegar a una información muy completa, que cubre desde la visualización del conjunto de la provincia hasta el detalle de cada geografía local, con todo su aparato explicativo y hermenéutico adicional.

Cada piedra sagrada se halla, por lo demás, prolijamente contextualizada, conforme a estos criterios:

\author{
Descripción \\ Historia \\ Leyenda y tradición oral \\ Acceso \\ Entorno \\ Estado de conservación \\ Información adicional \\ Galería [fotográfica]
}

Señalan los constructores del proyecto, con toda la razón, que estamos ante

un trabajo pionero, en vías de desarrollo, abierto a mejoras y modificaciones. Los objetivos futuros se centran en promover nuevas investigaciones que contribuyan a una mayor definición y enriquecimiento del concepto de «piedras sagradas» desde la perspectiva de diferentes disciplinas científicas, así como en estudiar propuestas de inclusión de nuevos lugares en el mapa. Por último, se pretende extender la experiencia a otros territorios.

Así es: la estructura del portal permite la incorporación futura de nuevos recursos tecnológicos y de cuanta información adicional se vaya generando, sobre piedras o conjuntos de piedras que se puedan aún localizar, o sobre la historia, la geografía, la etnografía del los que ya hay. Podrían, por ejemplo, ser añadidos bibliografías, videos además de fotografias, filmaciones con entrevistas a lugareños y, ¿por qué no? a arqueólogos e investigadores. Y se podría también exportar el concepto, la estructura, la tecnología, a otras provincias y entornos. Si todas las áreas territoriales y culturales de nuestro país e, idealmente, del mundo, contasen con instrumentos de recuperación y de conocimiento del patrimonio de la calidad de este, el salto adelante podría ser calificado de revolucionario.

Pero además, y puestos a soñar, podrían ser incorporadas informaciones no solo acerca de piedras sagradas. También acerca de espacios con leyendas de brujas y demonios, de apariciones de moras, moros, duendes y gigantes, de tesoros escondidos, de puentes del diablo, de prodigios, milagros e imágenes, de enfrentamientos en la época de las guerras de independencia o carlistas o de la guerra civil de 1936-1939. Y así hasta que se pudiera cubrir toda la variadísima casuística de las creencias y de los relatos tradicionales y se pudiera avanzar en una ideal arqueología de la memoria y en un completo mapa interactivo del imaginario colectivo.

Los cimientos de este sueño están ya sólidamente establecidos, y son generosamente ofrecidos por sus promotores a quienes deseen aprovecharlos y continuar la labor. Tres nombres importantísimos de la etnografía española contemporánea han contribuido a él: Eugenio Monesma Moliner, José Miguel Navarro López y Josefina Roma Riu han elaborado las completísimas fichas y han hecho las fotografías que 
acompañan a cada uno de los espacios catalogados en este portal. Si lo han conseguido con este nivel de perfección técnica ha sido gracias a la ayuda de los especialistas en divulgación territorial Pablo Alfonso Matute y Ramón Salanova Aznar (ECAS Técnicos Asociados SLP-www.aragonvirtual.es). En la concepción y en todas las fases de elaboración del proyecto ha estado y está Ángel Gari, uno de los pensadores que con mayor originalidad y profundidad han contribuido a la recuperación y al conocimiento de la cultura popular, en sus vertientes antropológica, etnohistórica y geográfica, de Aragón y de toda España.

Se anuncia ya una inminente ampliación de contenidos, que permitirá el acceso a una nueva categoría de «conjuntos sagrados territoriales», es decir, de escenarios míticolegendarios que serán mostrados sobre un mapa con capas interpretativas y contextuales, con panorámicas aéreas y fotografías panorámicas de $360^{\circ}$. Se atenderá en esa nueva (que no será la última) versión a más piedras, y quedará fijada una ruta turística por las cercanías de Huesca que tendrá en cuenta diversas piedras sagradas y otros elementos patrimoniales y paisajísticos de interés.

Sin el apoyo incondicional de la Diputación Provincial de Huesca y, en particular, del benemérito Instituto de Estudios Altoaragoneses, que es una de las instituciones culturales más activas, sensibles, avanzadas y mejor orientadas que hay en nuestro país, nada de esto hubiera sido posible.

\author{
José Manuel Pedrosa \\ (Universidad de Alcalá)
}

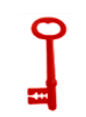

